\title{
The effect of taoist meditation on fatigue and physiologic stress in two people with multiple sclerosis: a case report
}

\author{
Linda Csiza* \\ Physical Therapy, Texas Woman's University, USA
}

\begin{abstract}
Background: Fatigue is a consistent symptom in persons with Multiple Sclerosis (MS), and medical interventions for fatigue have limited success. Moderate stress can lead to an exacerbation in people with MS, potentially resulting in increased disability. Meditation has been used in the treatment of chronic conditions.

Study objective: The purpose of this study was to determine the effect of meditation on fatigue and physiologic stress in persons with MS.

Participants/Methods: Two participants in the study will be described in this case report. One participant has Relapsing Remitting Multiple Sclerosis and the other has Secondary Progressive Multiple Sclerosis. Outcome measures, the Fatigue Severity Scale (FSS) and the Fatigue Visual Analogue (FVA), were completed during five different times in the study. Physiologic stress was measured using HR and BP and collected a total of 14 times during the study. The intervention was a 90 minute weekly Taoist meditation class offered at an area health care clinic. Analysis of the data was a combination of visual, descriptive methods, and statistical analysis.

Results: Both participants demonstrated improvement on the FSS and the FVA indicating a reduction in fatigue. One participant had a decrease in HR and BP by the end of the intervention. Both participants completed the meditation class regardless of level of disability or type of MS.

Conclusion: The two participants in this case report showed improvement in fatigue following the meditation. Statistical significance in the reduction of HR and BP were seen in after class recordings in one participant indicating a reduction of physiologic stress. The results indicate meditation could be beneficial to people with MS to combat the effects of fatigue and physiologic stress.
\end{abstract}

\section{Introduction and Background}

\section{Overview}

Multiple Sclerosis (MS) is an autoimmune demyelinating disease of the central nervous system of unknown etiology [1-6]. The disease affects about 400,000 individuals in the United States and ranks as the major cause of neurological disability among young adults between the ages of 15-45 years [1-7]. MS, like other presumed autoimmune diseases, is more common in females with the first clinical manifestation occurring in young adulthood. The clinical manifestations of MS are diverse, and symptoms include fatigue, numbness and weakness, paralysis, tremor, ocular motor deficits, disturbances in speech, bladder problems, and cognitive deficits [1-6].

MS is classified into 5 main types: relapsing-remitting MS (RRMS), secondary-progressive MS (SPMS), primary-progressive MS (PPMS), progressive-relapsing MS (PRMS), and benign MS (BMS) [1]. Relapsing-remitting multiple sclerosis, occurring in eighty-five to ninety percent of all individuals with MS, consists of exacerbations or attacks with recovery of all or much of lost function [1]. Secondaryprogressive multiple sclerosis begins as RRMS and with time progresses to a more permanently disabling course of the disease [1]. Primaryprogressive multiple sclerosis begins as a progressively degenerative disease with a constant loss of function and no true episodes of exacerbation [1]. Benign multiple sclerosis is a mild form of RRMS with occasional exacerbations followed by a complete or near complete recovery resulting in minimal loss of function for many years [1].

One of the most common and devastating symptoms of MS is fatigue which is reported by seventy to ninety percent of all individuals with MS [2-8]. For more than fifty percent of individuals with MS, fatigue is the most annoying symptom as well as the most common reason for disability [2-8]. Often the first symptom realized by the individual long before the diagnosis of MS, fatigue is usually greater in the second part of the day and worsened by stress [6]. Fatigue may occur at any point of the disease process in MS, and is more severe in individuals with PPMS and SPMS than in persons with RRMS $[9,10]$.

Fatigue is often managed medically with the use of multiple drugs with varying results. Amantadine, modafinil, pemoline, fampridine (4-AP), and 3,4-Di-aminopyridine (3,4-DAP) are commonly used medications for the treatment of fatigue [3,9,11-21]. These medications are associated with common side effects such as headache, constipation, nausea, dryness of mouth, thirst, loss of appetite, and confusion and anxiety. Rare side effects of these drugs may include restlessness, sleep disorders, visual hallucinations, urinary retention, heart failure, vertigo, weight loss, tremor, tachycardia, and seizures. Other types of interventions for the symptom of fatigue include exercise, yoga, energy conservation, and the use of a cooling suit $[22,23]$. All of these interventions have limited benefit in controlling MS-related fatigue.

Correspondence to: Linda Csiza, PT, DSc, NCS, Physical Therapy, Texas Woman's University, 5500 Southwestern Medical Ave, Dallas, TX 75235, USA, Tel: 972-653-2235; Fax: 214-689-7703; E-mail: lcsiza@twu.edu

Received: October 30, 2015; Accepted: November 26, 2015; Published: November 30, 2015 
The definitive cause of MS or the trigger of exacerbation of symptoms has not yet been determined. A concept first considered in 1877 by JM Charcot [24] is psychological stress may trigger disease activity in persons with MS. Many persons with MS believe clinical exacerbations may be related to stressful life events [24]. Mohr et al. [24] observed a significant relationship between moderately stressful life events characterized by conflict and disruption of daily routines, and the appearance of new gadolinium enhancing $(\mathrm{Gd}+)$ brain lesions four to eight weeks later. Moderate stress may be accompanied by immune suppression and followed by immune activation [24,25].

The chronic nature of MS, its unpredictable manifestations of symptoms, and the lack of a cure for the disease may all be perceived as stressful events. These stressors along with normal daily life stressors may have consequences leading to further disabling symptoms of the MS disease process.

People with MS should identify methods to reduce daily fatigue and to control daily stress in their lives. Meditation is an intervention successfully utilized in other chronic illnesses such as hypertension, fibromyalgia, and anxiety disorders [26-33] with benefits including reduction in pain, hypertension, anxiety, and improved cardiovascular function. An extensive search of the literature revealed a few studies utilizing some type of mind-body therapy for symptomatic relief of fatigue or stress management in persons with MS [34-39]. The studies utilized varying forms of mind-body therapies such as meditation, relaxation, breath work, visual imagery, yoga and relaxation. The benefits of these techniques included improvement in depression, anxiety, fatigue and quality of life $[36,38,39]$.

There are many different types of meditation; Zen, Buddhist, Taoist, Mindfullness, Transcendental meditation, Zazen, Vipassana, and Siddha Yoga [40,41]. These practices often involve differing techniques, but have as a commonality the focus of quieting the busy mind.

The purpose of the study was to determine if Taoist meditation had an effect on physiologic stress, heart rate (HR), blood pressure (BP), and the perception of fatigue in individuals with Multiple Sclerosis (MS). The hypotheses of this study were:

Hypothesis 1: The addition of Taoist meditation to the daily activities of individuals with MS would decrease the level of physiologic stress of the person as measured by a reduction in HR and BP.

Hypothesis 2: Incorporating daily Taoist meditation would cause a decrease in the perception of fatigue in individuals with MS as measured with the Fatigue Severity Scale (FSS) and the Fatigue Visual Analogue (FVA).

\section{Participants/methods}

Individuals between the ages of 21 to 75 years of age with a definite diagnosis of MS, either RRMS, PPMS, SPMS diagnosed by a neurologist, were included in the study. Exclusion criteria were active exacerbation at the start of the study, more than three exacerbations in the past year, and currently participating in meditation. Nine individuals who met the criteria were recruited. The 2 participants included in this case report read and signed the informed consent statement and were enrolled in the study. Internal Review Board (IRB) approval was obtained from associated institutions.

The participants completed a baseline period for data collection followed by an intervention period. The first participant (A) was female, age 47 with a diagnosis of RRMs for 13 years. The second participant (B) was male, age 56 with a diagnosis of SPMS for 24 years.
The Expanded Disability Severity Scale (EDSS), a measure of disease severity, was administered at the beginning of the study and at the end of the intervention [42].

The dependent variables included the Fatigue Severity Scale (FSS) and the Fatigue Visual Analogue Scale (FVA). The FSS scale asks the person to answer questions related to fatigue over the last week. The questions relate to motivation, exercise, physical functioning, activities during the day, and work and family. Each question is measured with a Likert scale from 1 (no fatigue) to 7 (the most severe fatigue experienced). A summed score is used for analysis and may range from 9 (no problem from fatigue) to 73 (severe problem from fatigue) [43-45]. The FVA uses a $17 \mathrm{~cm}$ line, marked in 1 centimeter segments, rating fatigue from no fatigue- 0 (the individual has the energy to do everything) to severe fatigue-17 (the individual must rest frequently throughout the day and is unable to participate in activities) [44]. The person places a mark on the line indicating the level of fatigue.

The baseline period was utilized to complete the FSS and the FVA. These measures were completed at the beginning of the baseline phase and at the end of the baseline phase. The same outcome measures were also completed during the eighth week of the study, the end of the intervention phase, and at the four week follow-up.

The HR and BP data were collected every five days during the baseline period. The beginning of the baseline occurred on a Monday. The data were collected on Monday $(\mathrm{M})$ and Friday (F) on oddnumbered weeks (weeks one, three, five, and seven), and on Wednesday (W) on even-numbered weeks (weeks two, four, and six). During the intervention phase of the study, $\mathrm{HR}$ and $\mathrm{BP}$ were taken before the meditation class and immediately following each class by a research assistant (CM recorded $\mathrm{HR}$ ) and the principal investigator (recorded $\mathrm{BP}$ and HR).

Open-ended questions on wellness, exacerbations, medication changes, and the benefit of medication were used during the intervention phase. These questions provided some insight into the participants' opinion on the benefit of meditation. The participants were required to keep a meditation diary recording the amount of time spent meditating at home along with responses to the open-ended questions.

Following the baseline period the participants began the intervention period which consisted of meditation in a class setting and at home. The meditation class was 90 minutes long and occurred once a week for 7 or 11 weeks, with daily home meditation for a minimum of 30 minutes per day. The class was led by an experienced Taoist meditation teacher. The participants recorded the time meditated and answered questions related to symptoms and benefit from meditation in a $\log$.

The study took place at an area clinic. The meditation class included the study participants, their significant others, the meditation teacher, the two research assistants, and the principal investigator. Class size was a maximum of 15 individuals.

\section{Analysis}

The data were graphed using Microsoft Office Excel 2003. A combination of visual, descriptive, and statistical analyses were used to analyze the data. Visual analysis looked at the trend of the raw data points, and trend lines were constructed using the logarithmic format in Microsoft Excel 2003. Descriptive analysis included the use of slope, when appropriate, to determine the average amount of change that 
occurred within a phase. The $\mathrm{R}$ equation was utilized to analyze the slopes of the lines.

The FVA was measured with a ruler to provide a data point for each mark on the scale. These points ( 0 -no fatigue to $17 \mathrm{~cm}$-severe fatigue) were plotted on a trend line for visual observation of trends, and slope [46]. To determine meaningful change in the FVA, percentage of change was calculated. For this study, it was determined that a $10 \%$ change in the FVA indicated a clinically relevant change related to the FVA. Scores from the FSS were plotted for visual observation of trends, and slope [46]. Visual and descriptive analysis of trend lines and slopes were performed on specific outcome measures data points (Figures 2 and 3).

Successive observations in a time series tend to be correlated, so HR and BP data were examined for serial dependency using the method described by Ottenbacher [47]. No significant trend was identified for baseline HR and BP data, so the C-statistic was used to look for a difference in HR and BP between phases. A Z-score was utilized to determine if the C-statistic was significant. For any data series with 8 or more data points, a Z-score of 1.64 or greater was statistically significant [47].

\section{Results}

The two participants completed the baseline period and the intervention period and returned for the 4 week follow up (Table 1). Both participants reported fatigue at the beginning of the study with baseline scores of 35-39 for participant A and 44-49 for participant $\mathrm{B}$ (lower score $=$ less fatigue) on the FSS. The baselines for both participants increased slightly from beginning of baseline to end of baseline indicating an increase in fatigue (Table 2).

A negative slope for the FSS indicates a reduction in fatigue (Figure 1). Both participants showed improvement in the symptom of fatigue as measured by the FSS. The four week follow-up data for the FSS remained unchanged in both participants (Table 2).

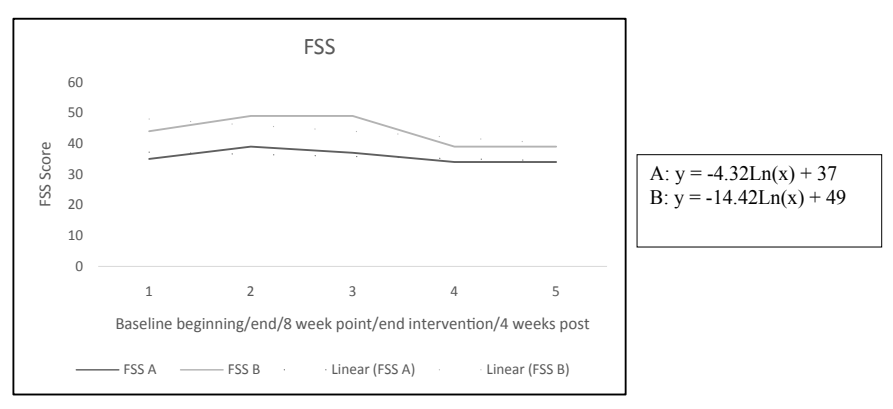

Figure 1. FSS trend and slope.

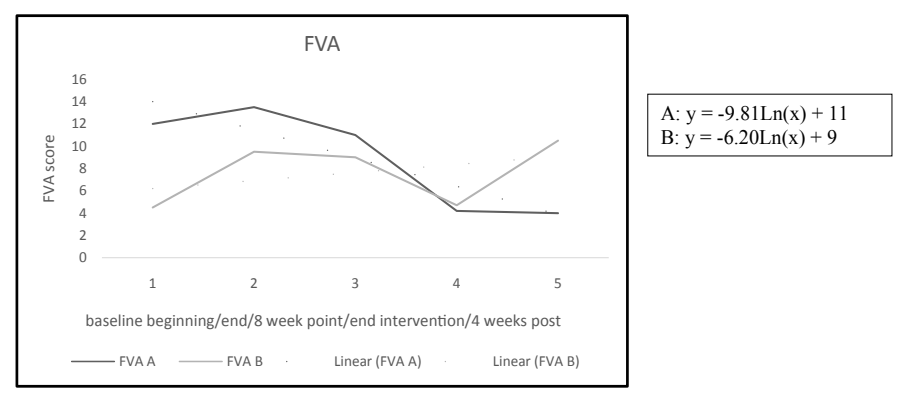

Figure 2. FVA trend and slopes.
Table 1. Demographic characteristics.

\begin{tabular}{|c|c|c|c|c|c|c|}
\hline G & $\begin{array}{c}\text { Age } \\
\text { Age }\end{array}$ & M/F & Type of MS & Length of MS & Medications & EDSS \\
\hline A & 47 & F & $\begin{array}{c}\text { Relapsing } \\
\text { Remitting }\end{array}$ & 13 years & $\begin{array}{c}\text { Birth Control Pills, } \\
\text { Avenox }\end{array}$ & 1.5 \\
\hline B & 56 & M & $\begin{array}{c}\text { Secondary } \\
\text { Progressive }\end{array}$ & 24 years & $\begin{array}{c}\text { Copaxone, } \\
\text { Baclofen, Kepra }\end{array}$ & 7.5 \\
\hline
\end{tabular}

Table 2. FSS and FVA scores.

\begin{tabular}{|l|c|c|c|c|c|}
\hline FSS & baseline & end of baseline & week 8 & end intervention & 4 week follow up \\
\hline A(RRMS) & 35 & 39 & 37 & 34 & 34 \\
\hline B(SPMS) & 44 & 49 & 49 & 39 & 39 \\
\hline FVA & baseline & end of baseline & week 8 & end intervention & 4 week follow up \\
\hline A(RRMS) & 12 & 13.5 & 11 & 4.2 & 4 \\
\hline B(SPMS) & 4.5 & 9.5 & 9 & 4.7 & 10.5 \\
\hline
\end{tabular}

The second measure of fatigue used in this study was the FVA. The baseline period for both participants showed a slight increase in the FVA from beginning of baseline to end of baseline indicating a slight worsening in fatigue (Table 2). Participant B had an increase of $29 \%$ on the FVA during the baseline period.

By the end of the intervention phase both of the participants had a significant reduction of fatigue measured by the FVA (Table 2) Participants A had a decrease on the FVA of 55\%, and participant B had a $32 \%$ reduction in perception of fatigue measured by the FVA.

The four week follow-up point showed differences between the participants. There was a worsening in fatigue from end of intervention to four weeks post in participant B with a $34 \%$ increase in the perception of fatigue. Participant A had an improvement in fatigue. Participant A report she had continued to meditate during the four week post period even though she was instructed to stop.

Analysis of slopes during intervention for the FVA indicated an improvement in the perception of fatigue in both participants as measured by the FVA (Figure 2). A negative slope in the line indicated an improvement in the symptom of fatigue.

The key data points for $\mathrm{HR}$ and BP used for analysis and observation were the baseline HR and BP measures and those obtained at the beginning and end of each class. Comparison of baseline means to four week follow-up was performed to identify changes across time to determine if meditation reduced HR and BP at the end of the meditation session and maintained the reduction at the four week follow-up.

During the study, before and after class, $\mathrm{HR}$ and BP were collected. $\mathrm{HR}$ and $\mathrm{BP}$ were analyzed for autocorrelation during the baseline phase and the intervention phase. No significant trend was identified for baseline HR and BP data, so the C-statistic was used to look for significance between phases. Before addressing the differences between the two phases (baseline and intervention), the C-statistic was run separately for the data before class and the data after class. If identified, a statistically significant change that occurred in the before class data would indicate a change over time related to the intervention. If a statistically significant change occurred in the after class data, a change directly related to that meditation class would be indicated.

When using the C-statistic to look for significance between phases, 
the baseline and intervention data are grouped together as total scores. First, the C-statistic, standard error, and Z-score are reported for both participants (Table 3) for the baseline and before class data. Participant A had a significant decrease in systolic BP.

The analysis of HR and BP was performed between the baseline scores and the after class scores. The after class scores are the scores indicating an immediate effect from the intervention. Participant B had a significant decrease in HR from end of baseline and immediately after meditation class. Participant B also had a significant reduction in systolic blood pressure and diastolic BP. A reduction in HR and BP correlates to a reduction in the perception of life stress immediately following the meditation class.

The meditation log was reviewed following the completion of the study. Each participant was asked to meditate for 30 minutes per day seven days per week for a total of 210 minutes per week. Average time meditated was 170 minutes per week. The majority of comments documented on the meditation daily record were positive in nature. Examples include: improvement in fatigue, ability to sleep better, able to stay focused longer during the day, and meditation has "a calming and relaxing feeling." There were a few negative comments such as "unable to calm my mind" and "I hate sitting still."

At the four week follow-up participant A stated she continued her meditation practice. Participant B had stopped meditating according to the protocol of the study which required meditation only during the intervention phase and not during the follow up period. Participant A reported meditation was now a part of her daily activities.

\section{Discussion}

Fatigue is often the biggest concern for people with MS and was identified as a problem for the participants of this study [2-8]. Results of this study identified worsening fatigue during baseline phases and positive consistent trends toward improvement in fatigue during the intervention phases for both participants measured by the FSS and the FVA. Specifically, during the baseline phase of the study some fluctuations in the FSS were identified. The mean difference of baseline FSS was 4.5 -points which is less than a $7 \%$ change. In this study an estimated meaningful change in the FSS was determined to be a 7-point change indicating a $10 \%$ change in the scale. To date the Minimally Detectable Change has not been established in the FSS. For the purpose

Table 3. C-Statistic for HR Total, Systolic and Diastolic BP Total.

\begin{tabular}{|l|c|c|c|}
\hline SUBJECT & C-STATISTIC & STANDARD ERROR & Z-SCORE \\
\hline A Before class & & & \\
HR & .12 & .23 & .54 \\
Systolic & .42 & & $1.9^{*}$ \\
Diastolic & .02 & & .09 \\
\hline AAfter class & & & \\
HR & .09 & .23 & .40 \\
Systolic & .18 & & .78 \\
Diastolic & .06 & & .26 \\
\hline B Before class & & & \\
HR & .14 & & .63 \\
Systolic & .33 & .24 & 1.5 \\
Diastolic & .22 & & 1.0 \\
\hline B After class & .71 & & $2.9^{*}$ \\
HR & .84 & & $3.5^{*}$ \\
Systolic & .90 & & $3.8^{*}$ \\
\hline Diastolic & & & \\
\hline
\end{tabular}

* indicates significance at $\mathrm{p}<0.05$, and $\mathrm{Z}$-score $\geq 1.64$. [47] of this study, a $10 \%$ change in the FSS was utilized to determine meaningful change.

The FSS improved by five points to ten points from end of baseline to end of the intervention. A five point change does not indicate at least a $10 \%$ improvement in the symptom of fatigue; however, a 10 point change signifies a $16 \%$ improvement.

The second measure of fatigue, the FVA, required the participants to mark the level of fatigue on a line. Differences were noted during the baseline period in one participant $B$ with an increase by five $\mathrm{cm}$ on the FVA indicating a $30 \%$ increase in fatigue. Thirty percent is a large increase in the symptom and may have been related to challenging life circumstances occurring during the time of the study accounting for the large increase in fatigue. Participant B was a graduate student and reported during the baseline phase that he was completing a major assignment for school. This event could have led to the increase in fatigue documented by the FVA. By the end of the intervention phase participant $\mathrm{B}$ had a decline in perception of fatigue by $28 \%$ approximately back to baseline on the FVA. The rigor of the graduate program did not lessen during the study, according to the meditation $\log$ and comments of the participant. However, there was a decrease in the perception of fatigue by the end of the intervention, indicating the meditation had a positive effect on fatigue even during challenging life events.

Both participants improved their FVA score from the end of baseline to the end of the intervention. Participant B had an increase in fatigue at the four week follow-up and he had SPMS which is similar to PPMS and is progressive in nature with no remissions. PrimaryProgressive MS is constantly progressive in nature, and with increasing disability there is increasing fatigue [48-50]. Participant A had a .5 point reduction in fatigue at the four week follow-up.

The reduction of fatigue in this study is of clinical importance. Fatigue is one of the strongest complaints and the number one reason for disability and retirement among individuals with MS [2-8]. A decrease in perceived fatigue could lead to improvement in multiple aspects of life in these individuals allowing them increased participation in life activities due to increased energy.

Like fatigue, stress is an important issue for people with MS since studies have shown a connection between moderate life stress and exacerbation [24,51]. Daily physiologic stress was measured by HR and $\mathrm{BP}$ during the meditation class. The short term effects of meditation were identified through analysis of baseline $\mathrm{HR}$ and $\mathrm{BP}$ and post-class $\mathrm{HR}$ and BP. Both participants were in the normal range for HR and BP during the baseline phase. Normal range for HR is $60-100$ beats per minute for the average adult and BP is reported as: optimal $<120 /<80$, normal $<130 /<85$, and high normal 130-139/85-89 [52].

Variability was noted during the baseline in HR and systolic and diastolic BP in both participants. The fluctuation of HR and BP seen is similar to a normal fluctuation which occurs in all people. HR and $\mathrm{BP}$ can fluctuate with activity during the day with daily stressors. These results were expected.

Observation of systolic and diastolic scores for participant A from the fifth week of the study to the end of the intervention identified the before class BPs were in the high range. It is interesting to note the change following the meditation class. Following every meditation class, this individuals $\mathrm{HR}$ and $\mathrm{BP}$ reduced into normal ranges (i.e., before- HR-88, after-HR-74, before BP 142/90, after BP 128/78 on week 5. By the end of the study, and at the four week follow up, this person's 
Table 4. HR/BP.

\begin{tabular}{|c|c|c|c|c|c|c|c|c|c|c|c|c|c|}
\hline A & HR Before & HR after & $\mathrm{r}$ & Sys before & $\begin{array}{c}\text { Sys } \\
\text { After }\end{array}$ & $\mathrm{r}$ & $\begin{array}{c}\text { Dia } \\
\text { Before }\end{array}$ & $\begin{array}{l}\text { Dia } \\
\text { after }\end{array}$ & $\mathrm{r}$ & B & $\begin{array}{l}\mathrm{HR} \\
\mathrm{F} / \mathrm{U}\end{array}$ & $\begin{array}{l}\text { Sys } \\
\text { F/U }\end{array}$ & $\begin{array}{l}\text { Dia } \\
\text { F/U }\end{array}$ \\
\hline 1 & 76 & 72 & .05 & 122 & 120 & .30 & 74 & 72 & .04 & .60 & 72 & 124 & 72 \\
\hline 2 & 78 & 70 & & 128 & 124 & & 78 & 72 & & & & & \\
\hline 3 & 88 & 82 & & 128 & 124 & & 78 & 74 & & & & & \\
\hline 4 & 78 & 74 & & 132 & 128 & & 80 & 78 & & & & & \\
\hline 5 & 88 & 74 & & 142 & 128 & & 90 & 78 & & & & & \\
\hline 6 & 78 & 72 & & 130 & 124 & & 80 & 72 & & & & & \\
\hline 7 & 120 & 88 & & 160 & 138 & & 100 & 80 & & & & & \\
\hline 8 & 86 & 78 & & 140 & 132 & & 80 & 76 & & & & & \\
\hline 9 & 88 & 78 & & 150 & 132 & & 100 & 84 & & & & & \\
\hline 10 & 84 & 74 & & 142 & 132 & & 80 & 74 & & & & & \\
\hline 11 & 82 & 68 & & 138 & 128 & & 78 & 72 & & & & & \\
\hline B & HR Before & HR after & $\mathrm{r}$ & Sys before & $\begin{array}{c}\text { Sys } \\
\text { After }\end{array}$ & $\mathrm{r}$ & $\begin{array}{l}\text { Dia } \\
\text { Before }\end{array}$ & $\begin{array}{l}\text { Dia } \\
\text { after }\end{array}$ & $\mathrm{r}$ & B & $\begin{array}{l}\mathrm{HR} \\
\mathrm{F} / \mathrm{U}\end{array}$ & $\begin{array}{l}\text { Sys } \\
\text { F/U }\end{array}$ & $\begin{array}{l}\mathrm{Dia} \\
\mathrm{F} / \mathrm{U}\end{array}$ \\
\hline 1 & 78 & 70 & .30 & 124 & 120 & .05 & 74 & 72 & .25 & .75 & 74 & 120 & 72 \\
\hline 2 & 66 & 62 & & 122 & 116 & & 74 & 70 & & & & & \\
\hline 3 & 66 & 58 & & 122 & 114 & & 72 & 66 & & & & & \\
\hline 4 & 78 & 58 & & 122 & 116 & & 78 & 68 & & & & & \\
\hline 5 & 76 & 68 & & 124 & 118 & & 74 & 68 & & & & & \\
\hline 6 & 76 & 68 & & 126 & 118 & & 78 & 66 & & & & & \\
\hline 7 & 78 & 68 & & 124 & 114 & & 78 & 66 & & & & & \\
\hline
\end{tabular}

Sys: Systolic BP

Dia: Diastolic BP

r: r value

B: Bartlett's test

HR and BP had again normalized (end of intervention: 68, 128/72; 4 week follow up: 72, 124/72). Even though this individual's BP was in the high range before class, it always normalized by the end of class. This individual reported the meditation helped to combat the daily stress level that occurred from work and home environments.

Analysis of the C-statistic for HR and BP showed significance in four measures in after class HR and BP data. When looking at the points of significance for after class data participant B demonstrated significant results in all three measures. This individual had SPMS and used a power wheel chair as primary mobility. The EDSS score for this person was the high at 7.5, indicating a lower level of activity and higher level of disability. The meditation may have helped this individual show statistically significant reductions in HR and BP indicating countering the daily effects of inactivity due to disability from the meditation. This is a clinically relevant result because individuals with a higher level of disability from MS are unable to participate in aerobic training programs to help improve HR and BP. These data provide some evidence that meditation can counter some of the effects of deconditioning in MS as seen in other diseases [22,24-26,41,42].

This study had a short intervention period of 7 weeks in participant $\mathrm{B}$ and 11 weeks in participant $\mathrm{A}$. This is a short time frame for determining lasting changes in HR and BP as well as changes on other outcome measures. Meditation is a skill that requires learning and practice, and it is difficult to determine when the learning occurred in the participants. Learning the technique probably occurred during the class sessions where the individuals could ask questions related to meditation. The class interaction, the group effect, and meditating at home could all have influenced when learning the technique occurred. Once the technique of meditation was learned the improvement in the measures might have occurred at a faster rate.
The participant with RRMS did not consistently demonstrate a significant and lasting change in HR and BP. This may be due to the short length of intervention phase for both participants. A long term randomized controlled trial including individuals with any type of MS with increased time for gathering data may identify a lasting benefit in reduction of $\mathrm{HR}$ and $\mathrm{BP}$ as seen in other studies [27,29-31,33].

This is a case report that identifies in two people with different types of MS some benefit from meditation in the perception of fatigue and physiologic stress. Suggestions for future studies include the use of a large sample, randomization of subjects, inclusion of a control group, and longer length of intervention. It would also be beneficial to compare meditation to other types of interventions such as different types of exercise and medication. Many of the participants indicated meditation might be helpful in lowering fatigue and physiologic stress, but felt they needed more time both in the meditation class and meditating at home [53-57].

\section{Conclusion}

The study shows some support that meditation can cause changes in HR and BP which may be attributed to a reduction in physiologic stress in people with MS. Also incorporating daily Taoist meditation resulted in a decrease in the perception of fatigue in two individuals with MS. Fatigue is the main cause of disability in individuals with MS, and the reduction of fatigue could lead to the maintenance of an active lifestyle [2-8].

Meditation is a technique that can become a part of daily activity in someone with MS. It requires no equipment, utilizes little energy, can be performed anywhere, providing the individual with a sense of control over life. 


\section{Acknowledgements}

I would like to acknowledge Heather Ellott who assisted with the editing of this article and the participants in this study whose time and efforts are greatly appreciated.

\section{Conflict of interest}

The author has no conflict of interest to disclose.

\section{References}

1. (2001) Multiple Sclerosis the ultimate user-friendly guide. (2ndedn), Murray RS, Shaughnessy L, Haruf K (Ed.), Englewood: Biogen.

2. Colosimo C, Millefiorini E, Grasso MG, Vinci F, Fiorelli M, et al. (1995) Fatigue in MS is associated with specific clinical features. Acta Neurol Scand 92: 353-355. [Crossref]

3. Ford H, Trigwell P, Johnson M (1998) The nature of fatigue in multiple sclerosis. $J$ Psychosom Res 45: 33-38. [Crossref]

4. Freal JE, Kraft GH, Coryell JK (1984) Symptomatic fatigue in multiple sclerosis. Arch Phys Med Rehabil 65: 135-138. [Crossref]

5. Fisk JD, Pontefract A, Ritvo PG, Archibald CJ, Murray TJ (1994) The impact of fatigue on patients with multiple sclerosis. Can J Neurol Sci 21: 9-14. [Crossref]

6. Krupp LB, Alvarez LA, LaRocca NG, Scheinberg LC (1988) Fatigue in multiple sclerosis. Arch Neurol 45: 435-437. [Crossref]

7. Sandroni P, Walker C, Starr A (1992) 'Fatigue' in patients with multiple sclerosis. Motor pathway conduction and event-related potentials. Arch Neurol 49: 517-524. [Crossref]

8. Zifko UA (2004) Management of fatigue in patients with multiple sclerosis. Drugs 64: 1295-1304. [Crossref]

9. Comi G, Leocani L, Rossi P, Colombo B (2001) Physiopathology and treatment of fatigue in multiple sclerosis. J Neurol 248: 174-179. [Crossref]

10. Lerdal A, Celius EG, Moum T (2003) Fatigue and its association with sociodemographic variables among multiple sclerosis patients. Mult Scler 9: 509-514. [Crossref]

11. Bakshi R (2003) Fatigue associated with multiple sclerosis: diagnosis, impact and management. Mult Scler 9: 219-227. [Crossref]

12. Berger JR, Pocoski J, Preblick R, Boklage S (2013) Fatigue heralding multiple sclerosis. Mult Scler 19: 1526-1532. [Crossref]

13. Bever CT Jr, Anderson PA, Leslie J, Panitch HS, Dhib-Jalbut S, et al. (1996) Treatment with oral 3,4 diaminopyridine improves leg strength in multiple sclerosis patients: results of a randomized, double-blind, placebo-controlled, crossover trial. Neurology 47: 1457-1462. [Crossref]

14. Cohen RA, Fisher M (1989) Amantadine treatment of fatigue associated with multiple sclerosis. Arch Neurol 46: 676-680. [Crossref]

15. Gillson G, Richard TL, Smith RB, Wright JV (2002) A double-blind pilot study of the effect of Prokarin on fatigue in multiple sclerosis. Mult Scler 8: 30-35. [Crossref]

16. Goodman AD, Cohen JA, Cross A, Vollmer T, Rizzo M, et al. (2007) FampridineSR in multiple sclerosis: a randomized, double-blind, placebo-controlled, dose-ranging study. Mult Scler 13: 357-368. [Crossref]

17. Krupp LB, Coyle PK, Doscher C, Miller A, Cross AH, et al. (1995) Fatigue therapy in multiple sclerosis: results of a double-blind, randomized, parallel trial of amantadine, pemoline, and placebo. Neurology 45: 1956-1961. [Crossref]

18. Polman CH, Bertelsmann FW, van Loenen AC, Koetsier JC (1994) 4-aminopyridine in the treatment of patients with multiple sclerosis. Long-term efficacy and safety. Arch Neurol 51: 292-296. [Crossref]

19. Rammohan KW, Rosenberg JH, Lynn DJ, Blumenfeld AM, Pollak CP, et al. (2002) Efficacy and safety of modafinil (Provigil) for the treatment of fatigue in multiple sclerosis: a two centre phase 2 study. J Neurol Neurosurg Psychiatry 72: 179-183. [Crossref]

20. Rosenberg GA, Appenzeller O (1988) Amantadin, fatigue, and multiple sclerosis. Arch Neurol 14: 273-278.

21. Sheean GL, Murray NM, Rothwell JC, Miller DH, Thompson AJ (1998) An openlabelled clinical and electrophysiological study of 3,4diaminopyridine in the treatment of fatigue in multiple sclerosis. Brain 121: 967-975. [Crossref]
22. Flensner G, Lindencrona C (2002) The cooling-suit: case studies of its influence on fatigue among eight individuals with multiple sclerosis. $J$ Adv Nurs 37: 541-550. [Crossref]

23. Mathiowetz V, Matuska KM, Murphy ME (2001) Efficacy of an energy conservation course for persons with multiple sclerosis. Arch Phys Med Rehabil 82: 449-456. [Crossref]

24. Mohr DC, Goodkin DE, Bacchetti P, Boudewyn AC, Huang L, et al. (2000) Psychological stress and the subsequent appearance of new brain MRI lesions in MS. Neurology 55: 55-61. [Crossref]

25. Nisipeanu P, Korczyn AD (1993) Psychological stress as risk factor for exacerbations in multiple sclerosis. Neurology 43: 1311-1312. [Crossref]

26. Astin JA, Shapiro SL, Eisenberg DM, Forys KL (2003) Mind-body medicine: state of the science, implications for practice. J Am Board Fam Pract 16: 131-147. [Crossref]

27. Barnes VA, Treiber FA, Turner JR, Davis H, Strong WB (1999) Acute effects of transcendental meditation on hemodynamic functioning in middle-aged adults. Psychosom Med 61: 525-531. [Crossref]

28. Bishop SR (2002) What do we really know about mindfulness-based stress reduction? Psychosom Med 64: 71-83. [Crossref]

29. Dimsdale JE, Mills PJ (2002) An unanticipated effect of meditation on cardiovascular pharmacology and physiology. Am J Cardiol 90: 908-909. [Crossref]

30. Kabat-Zinn J, Massion AO, Kristeller J, Peterson LG, Fletcher KE, et al. (1992) Effectiveness of a meditation-based stress reduction program in the treatment of anxiety disorders. Am J Psychiatry 149: 936-943. [Crossref]

31. Kabat-Zinn J, et al. (1998) Influence of a mindfulness meditation-based stress reduction intervention on rates of skin clearing in patients with moderate to severe psoriasis undergoing photo therapy (UVB) and photochemotherapy (PUVA). Phychosom Med 60: 625-632.

32. Kaplan KH, Goldenberg DL, Galvin-Nadeau M (1993) The impact of a meditationbased stress reduction program on fibromyalgia. Gen Hosp Psychiatry 15: 284-289. [Crossref]

33. Miller JJ, Fletcher K, Kabat-Zinn J (1995) Three-year follow-up and clinical implications of mindfulness meditation-based stress reduction intervention in the treatment of anxiety disorders. General Hospital Psychiatry 17: 192-200. [Crossref]

34. Chalk HM (2007) Mind over matter: cognitive-behavioral determinants of emotional distress in multiple sclerosis patients. Psychol Health Med 12: 556-566. [Crossref]

35. Dayapoglu N, Tan M (2012) Evaluation of the effect of progressive relaxation exercises on fatigue and sleep quality in patient with multiple sclerosis. J Altern Complement Med 18: 983-987. [Crossref]

36. Grossman PKL, Gensicke H (2010) Multiple Sclerosis quality of life, depression and ftigue improve after mindfulness training: a randomized controlled trial. Neurology 75: 1141-1149.

37. Pritchard M, PattElison B, Birdsall B (2010) Impact of Integrative Restoration (iRest) meditation on perceived stress levels in multiple sclerosis and cancer outpatients. Stress and Health 26: 233-237.

38. Senders A, Wahbeh H, Spain R, Shinto L (2012) Mind-body medicine for multiple sclerosis: a systematic review. Autoimmune Dis 2012: 567324. [Crossref]

39. Wahbeh H, Elsas SM, Oken BS (2008) Mind-body interventions: applications in neurology. Neurology 70: 2321-2328. [Crossref]

40. ICBS, I. Holisticonline.com. 1998-2005 [cited 2005 August 14, 2005].

41. Ottenbacher KJ (1986) Visual analysis of single system data, in Evaluation Clinical Change Strategies for Occupational and Physical Therapists, Butler JP(Ed.), Williams and Wilkins: Baltimore 137-166.

42. Kurtzke JF (1983) Rating neurologic impairment in multiple sclerosis: an expanded disability status scale (EDSS). Neurology 33: 1444-1452. [Crossref]

43. Krupp LB, LaRocca NG, Muir-Nash J, Steinberg AD (1989) The fatigue severity scale. Application to patients with multiple sclerosis and systemic lupus erythematosus. Arch Neurol 46: 1121-1123. [Crossref]

44. Krupp L, et al. (1998) Fatigue measures for clinical trial in multiple sclerosis Neurology 50: pA126.

45. Krupp LB, LaRocca NG, Muir-Nash J, Steinberg AD (1989) The fatigue severity scale Application to patients with multiple sclerosis and systemic lupus erythematosus. Arch Neurol 46: 1121-1123. [Crossref] 
46. Portney L, Watkins M (1993) Experimental control, in Foundations of Clinical Research. In: Mehalik C, Davis K(Eds.), Appleton \& Lange: Norwalk.,141, 684.

47. Ottenbacher KJ (1986) Statistical analysis of single system data, in Evaluating Clinical Change Strategies for Occupational and Physical Therapists. In: Butler JP (Ed.), Williams and Wilkins: Baltimore.,167-195.

48. Koch M, Uyttenboogaart M, van Harten A, Heerings M, De Keyser J (2008) Fatigue, depression and progression in multiple sclerosis. Mult Scler 14: 815-822. [Crossref]

49. Motl RW, Arnett PA, Smith MM, Barwick FH, Ahlstrom B, et al. (2008) Worsening of symptoms is associated with lower physical activity levels in individuals with multiple sclerosis. Mult Scler (Houndmills, Basingstoke, England), 14: 140-142. [Crossref]

50. Patrick E, Christodoulou C, Krupp LB; New York State MS Consortium (2009) Longitudinal correlates of fatigue in multiple sclerosis. Mult Scler 15: 258-261. [Crossref]

51. Ackerman KD, Heyman R, Rabin BS, Anderson BP, Houck PR, et al. (2002) Stressful life events precede exacerbations of multiple sclerosis. Psychosom Med 64: 916-920. [Crossref]

52. Goodman C (2003)The Cardiovascular System, in Pathology Implications for the
Physical Therapist. In: Goodman C, Boissonnault W, Fuller K(Eds.), Sauders: Philadelphia, 396.

53. DeBolt LS, McCubbin JA (2004) The effects of home-based resistance exercise on balance, power, and mobility in adults with multiple sclerosis. Arch Phys Med Rehabil 85: 290-297. [Crossref]

54. Gehlsen GM, Grigsby SA, Winant DM (1984) Effects of an aquatic fitness program on the muscular strength and endurance of patients with multiple sclerosis. Phys Ther 64 : 653-657. [Crossref]

55. Mostert S, Kesselring J (2002) Effects of a short-term exercise training program on aerobic fitness, fatigue, health perception and activity level of subjects with multiple sclerosis. Mult Scler 8: 161-168. [Crossref]

56. Oken BS, Kishiyama S, Zajdel D, Bourdette D, Carlsen J, et al. (2004) Randomized controlled trial of yoga and exercise in multiple sclerosis. Neurology 62: 2058-2064. [Crossref]

57. Petajan JH, Gappmaier E, White AT, Spencer MK, Mino L, et al. (1996) Impact of aerobic training on fitness and quality of life in multiple sclerosis. Ann Neurol 39: 432-441. [Crossref]

Copyright: (C2015 Csiza L. This is an open-access article distributed under the terms of the Creative Commons Attribution License, which permits unrestricted use, distribution, and reproduction in any medium, provided the original author and source are credited. 